\title{
Low levels of faecal cortisol in bank voles (Myodes glareolus) in response to live-trapping
}

\author{
A. Acsai ${ }^{1 *}$, T. Drexler ${ }^{1 *}$, N.P. Evans ${ }^{2} \&$ D.J. McCafferty ${ }^{3}$ \\ ${ }^{1}$ Institute of Biodiversity, Animal Health \& Comparative Medicine, College of Medical, Veterinary and Life Sciences, \\ University of Glasgow, Graham Kerr Building, Glasgow G12 8QQ \\ ${ }^{2}$ Institute of Biodiversity, Animal Health \& Comparative Medicine, College of Medical, Veterinary and Life Sciences, \\ University of Glasgow, Jarrett Building, Glasgow G61 1QH
}

${ }^{3}$ Scottish Centre for Ecology and the Natural Environment, Institute of Biodiversity, Animal Health \& Comparative Medicine, College of Medical, Veterinary and Life Sciences, University of Glasgow, Rowardennan G63 0AW

*These two authors contributed equally to the study.

E-mail: dretom93@gmail.com (T. Drexler)

\begin{abstract}
Small mammal trapping is a commonly taught field technique in ecology and population biology. However, there are still open questions regarding the extent to which trapping affects the welfare of small animals. This study investigated faecal cortisol as a non-invasive measurement of the physiological stress response of bank voles (Myodes glareolus) to live-trapping. Faecal cortisol concentrations were similar between samples collected from trapped and non-trapped voles, but were negatively correlated with capture duration. This result may suggest that any physiological stress response was short-lasting and the animals habituated to the trap. As such, effects on faecal cortisol were not apparent as mean faecal cortisol concentration was determined from multiple collected faeces. Future work should focus on characterising the potential stress response to trapping with greater temporal resolution.
\end{abstract}

\section{INTRODUCTION}

Live-trapping is widely used as a basic method in ecology and population biology to study the species composition of animal communities (Pearson \& Ruggiero, 2003), for virological testing (Mills et al., 1995), and to estimate the density or range of a given species (Stickel, 1954; Wilson \& Anderson, 1985). This technique is also commonly used in animal relocation or translocation programmes, either in conservation biology (Teixeira et al., 2007), or where animals are considered as pests or invasive species (Bertolino \& Genovesi, 2003; Rosatte \& MacInnes, 1989).

It is important to understand how specific features of live-trapping affect animal welfare. Such features include type of the trap used, the timing of setting the traps and how long animals are held captive. Choosing the appropriate measurements to assess the potential impacts of live-trapping, however, is challenging. One of the most commonly used methods to assess the effect of trapping on small mammals is to record changes in body mass when repeated captures occur over consecutive days (e.g. Pavone \& Boonstra, 1985; Korn, 1987; Kaufman \& Kaufman, 1994; Lindner \& Fuelling, 2002; Pearson et al., 2003; Suazo \& Delong, 2007). Such studies have shown that being held within a live trap can cause significant body mass loss and that decreases in body mass are correlated with trap mortality and reduced survival (Pearson et al. 2003). It is important to note that, where live-trapping occurs over a prolonged period of time and if animals are trapped repeatedly, even small daily mass losses can be cumulative (Korn, 1987). In this respect, small rodents can be the most sensitive animals to effects of live-trapping, as they have a low body mass and high metabolism (Pearson, 1947; Nagy et al., 1999).

Another important method for assessing the impact of live-trapping, is the measurement of physiological stress (e.g. Kenagy \& Place, 2000; Koprowski, 2002; Fletcher \& Boonstra, 2006; Mellish, 2010; Bosson et al., 2012). Trapping is a known stressor that activates the body's stress responses including the hypothalamo-pituitaryadrenal (HPA) axis (Ortiz \& Worthy, 2000; Boonstra et al., 2001; Reeder et al., 2004). Activation of the HPA axis results in release of glucocorticoids (corticosterone/cortisol), which circulate within the blood and trigger a series of acute compensatory physiological adaptations that help the animal adapt to the stressor (e.g. increased circulating glucose levels which enhanced the capacity to flee from a stressor; National Research Council, 2008). It has been shown in meadow voles (Microtus pennsylvanicus) that plasma corticosterone concentrations are higher in animals captured in live traps as opposed to animals that are snap-trapped (Fletcher \& Boonstra, 2006). Harper \& Austad (2001) reported a positive relationship between the duration deer mice (Peromyscus maniculatus) are held captive in a live trap and glucocorticoid levels, but 
not in red-backed voles (Clethrionomys gapperi). Bosson et al. (2012) showed that in North American red squirrels (Tamiasciurus hudsonicus), cortisol concentrations were related to the duration of capture, and different trap models induced different physiological responses. In the light of these studies there is a need to determine an appropriate checking interval for studies of small mammals, as it is clear that trapping causes stress, but the effects of trapping duration can be different for different species. It has also been shown that successive stressors (e.g. prolonged captivity, noise pollution) can have additive or cumulative effects (Moberg \& Mench, 2000; Teixeira et $a l ., 2007)$ on a variety of body systems, affect cognitive abilities (McEwen \& Sapolsky, 1995; Mendl, 1999) and result in negative impacts on health and survival (Wey et al., 2015).

For investigation of an acute physiological stress response, glucocorticoid concentrations in blood or saliva samples are often used, but where more chronic measures are required it is also possible to measure glucocorticoids in samples of urine, faeces and hair (Abelson et al., 2005). When assessing the physiological response to a stressor it is important to note that the sample collection methods can themselves be stressful (National Research Council, 2008), and have the potential to confound the results of the assessment. This particularly applies to the collection of invasive samples such as blood and saliva for the measurement of acute stress. Laboratory studies on the domestic rat (Rattus norvegicus) suggest that glucocorticoid concentrations are elevated within three to five minutes following the initiation of a stressor such as handling (Dallman \& Bhatnagar, 2001). Similarly, it has been reported that in free-living vertebrates, blood samples must be collected within two minutes of capture to prevent any bias due to the effect of handling on glucocorticoid concentrations (Romero \& Reed, 2005).

Assessing glucocorticoids using faecal samples is a non-invasive way to examine stress in both free living and live-trapped individuals (National Research Council, 2008). An important benefit of faecal samples and the subsequent analysis of faecal glucocorticoids is that, unlike blood samples, which provide an instantaneous snapshot of glucocorticoid levels at a precise moment in time, faecal glucocorticoid concentrations provide an integrated measure of circulating glucocorticoids over a period of time. This time frame is influenced by the gut transit time of that species (Palme et al., 1996; von der Ohe \& Servheen, 2002), which is short in the case of small mammals (Clemens \& Stevens, 1980). Corticosterone metabolites can be detected in the faeces of red-backed voles for up to eight hours after a corticosteroid injection (Harper \& Austad, 2000). Similarly, corticosterone metabolites can be detected in Syrian hamster (Mesocricetus auratus) faeces after four hours (Chelini et al., 2010), and in mice (Mus musculus) two hours after ACTH injection (Touma et al., 2004). Faecal corticosterone metabolites can also be detected two hours after trap confinement in North American deer mice (Eleftheriou et al., 2020).
However, these studies did not investigate time points shorter than four and two hours respectively and therefore it is possible that corticosterone metabolites occur in the faeces even earlier. In live traps, given that small mammals may feed and gut transit time can be as little as 0.8 h (Brandt's vole, Microtus brandtii: Pei et al., 2001), there is the possibility of assessing the corticosteroid concentrations in faeces while the animals are captive.

The aim of this project was to assess how trapping with standard methods commonly used in ecological studies influences the physiological stress response of a small rodent species. We examined if capture itself leads to elevated cortisol concentrations in trapped animals compared with non-trapped individuals, and if cortisol concentrations in both males and females were proportional to the time spent in the traps. Faecal cortisol metabolites have been already validated and used in more rodent species for stress assessment (e.g. Bosson et al., 2009; Dantzer et al., 2010; Montiglio et al., 2012). We predicted that capture would increase faecal cortisol, and that faecal cortisol concentrations would be positively correlated with time spent in the trap (trap duration). We expected this relationship to be linear, or linear after a short delay associated with defaecation patterns. We chose the bank vole (Myodes glareolus) as a model species, because it is often used as a model species in ecological and evolutionary research. In addition, it occurs at relatively high densities and has a favourable conservation status (IUCN, 2016). The results of the study, however, have a wider relevance as they provide insight into how capture-induced stress in small rodents can be reduced.

\section{MATERIALS AND METHODS \\ Study site}

The study was conducted in an oak forest in Loch Lomond and the Trossachs National Park, Scotland in the vicinity of the Scottish Centre for Ecology and the Natural Environment (SCENE), University of Glasgow $\left(56.129836^{\circ} \mathrm{N}, 4.615282^{\circ} \mathrm{W}\right)$ from 4 th to 7 th June 2018.

\section{Sample collection from non-trapped individuals}

To collect samples for estimation of cortisol concentrations of non-trapped voles, we left 16 Ugglan traps (Grahnab AB, Sweden) overnight at the study site. This is a live-capture trap with an opening that lets only small rodents enter. The closing mechanism is based on a counter-weighted tilting door and allows the capture of multiple animals at the same time. This trap was chosen for our study because it is widely used in smallmammal studies and was reported to have higher efficiency and lower trap-induced mortality compared with Sherman traps (Jung, 2016). The doors of the traps were left open so that the animals could feed and defecate inside them without being caught. The use of the traps in this regard controls for any stress effect of the trap itself as opposed to a period of captivity within the trap.

Porridge oats mixed with peanut butter was placed inside the traps as bait, and a piece of apple as a water 
source. Bedding material was provided for insulation. The traps were placed on the ground in three transects in three different areas in the forest at $c a .5 \mathrm{~m}$ spacing, oriented towards a runway or burrow in the leaf-litter. Faeces found in each trap were collected into $2 \mathrm{ml}$ Eppendorf tubes and placed in a $-20^{\circ} \mathrm{C}$ freezer within half an hour after collection until cortisol analysis. Faeces belonging to bank voles were selected, based on their morphology as identified using MacDonald \& Barrett (1993). The droppings of this species are rounded, $0.8 \mathrm{~cm}$ long $\times 0.4 \mathrm{~cm}$ wide, and therefore can be distinguished from droppings of wood mouse (Apodemus sylvaticus) and yellow-necked mouse (A. flavicollis) by their smaller size. In contrast to the faeces of the field vole (Microtus agrestis), which is green and oval, those of the bank vole are brown to black. Traps were cleaned with soap and water before and after the first trapping session.

\section{Live-trapping}

The 16 Ugglan multi-capture traps were baited as before and placed in the previously used locations, but this time were set to catch animals. A DS1920-F5 temperature logger ibutton ${ }^{\mathrm{TM}}$ (Maxim Integrated, U.S.) was fixed to the back door of the trap with Velcro adhesive tape. The loggers were programmed to record temperature with $0.5^{\circ} \mathrm{C}$ precision every five minutes to detect body heat. Traps were set at 6:00 and were checked every day at $10: 00,14: 00,18: 00$ and 22:00, meaning that the maximal time an animal could spend in a trap was four hours. On one occasion an overnight (22:00-4:00) live-trapping session was conducted but, as the trapping success was no greater than during the day, this was not repeated. Live-trapping was conducted for a total of 46 hours. At each trap check, traps were cleaned and new bait and bedding placed into them.

In the case of a capture, the animal was transferred into a plastic bag and weighed with a Pesola spring balance $\pm 0.5 \mathrm{~g}$. Sex was determined from the length of the urogenital gap, which is greater in males than in females. Animals were then released at the site of capture and the traps were repositioned to reduce the chance of recapture. The time of release was noted to allow the duration of capture to be calculated. All droppings from within each trap were collected into an Eppendorf tube (one tube for each capture) and stored as described previously for subsequent analysis. All double captures (i.e. two different animals entered the same trap in the same trapping session) were not included in the further analysis.

\section{Estimation of the time spent in the traps}

The time at which the animal entered the trap and the duration of captivity were determined by analysis of the logged temperature data and the known time of release. Temperature data were plotted in Microsoft Excel (version 2010) from the time of the previous trap check to the time of release. Trap entry was estimated based on a method described by Weidinger (2006), which detected predation of songbird nest boxes by reporting the time of a permanent decline in nest temperature. In our case the time point of a $1{ }^{\circ} \mathrm{C}$ increase within five minutes, followed by a permanently elevated temperature, was defined to be the time of capture (Fig. 1).

\section{Stress assessment - ELISA cortisol assay}

Faecal cortisol was measured, following solvent extraction, using a commercially available ELISA (Cayman chemical Cortisol ELISA kit). This assay has a $100 \%$ cross reactivity with cortisol, $<5 \%$ cross reactivity with prednisolone, $<2 \%$ cross reactivity with cortexolone and $<0.3 \%$ cross reactivity with 17-hydroxyprogesterone, cortisol glucuronide, corticosterone, cortisone, androstenedione, enterolactone, estrone 17-hydroxypregnenolone pregnenolone and testosterone. Faecal samples were freeze dried (for 48 hours) and powdered using a ball mill (Retsch MM40, Retsch, Germany). Cortisol was extracted by placing 5-10 mg of each faecal sample into a glass tube and vortexing with $2 \mathrm{ml}$ methanol for 30 minutes. Following centrifugation for five minutes at $3000 \mathrm{rpm}$ the supernatant was decanted into a new clean glass tube. The methanol extraction of the faecal powder was repeated and the supernatants from the two extractions pooled. A $300 \mu \mathrm{l}$ aliquot of the methanol extract was dried down, before reconstitution in $500 \mu 1$ of assay buffer. An initial ELISA confirmed specificity of the assay for use with extracted vole faecal cortisol as determined by parallelism between a serial dilution of the faecal extract and the standard curve (Rogovin \& Naidenko, 2010). The dilution series was also used to ascertain the optimum volume/dilution of the extract such that the expected cortisol concentrations would fall within the range of the standard curve.

The Elisa assay was conducted as per the manufacturer's instructions. The optical density was determined with a Labtech LT-4500 plate reader at a wavelength of $405 \mathrm{~nm}$ and cortisol concentrations calculated using commercially available assay software (Assayzap, Biosoft Cambridge U.K.). The amount of cortisol in the faecal samples was calculated by correction for dilution and expressed in $\mathrm{ng} \mathrm{g}^{-1}$ dried faeces.

\section{Statistical analyses}

All statistical analyses were conducted using R software (Version 3.5.1, The $\mathrm{R}$ Foundation for Statistical Computing, 2018). The effect of capture on cortisol concentration was tested using the Mann-Whitney $U$ test, because the distribution of cortisol concentration did not fit a normal distribution. In the case of duration of capture, a linear mixed effect model was fitted, with faecal cortisol concentrations as the response variable and the duration of trapping as the explanatory variable. As the home range size of bank voles can range from 200 to $1600 \mathrm{~m}^{2}$ (Koskela et al., 1997), the possibility existed that voles captured within one transect at different times may be the same individual, therefore, a factor variable as a random effect was included in the model that classified observations into six groups (male and female voles captured in each of the three transects). Furthermore, analysis of the data pertaining to the time of capture and release within each transect indicated that no voles were subject to immediate recapture (and thus 


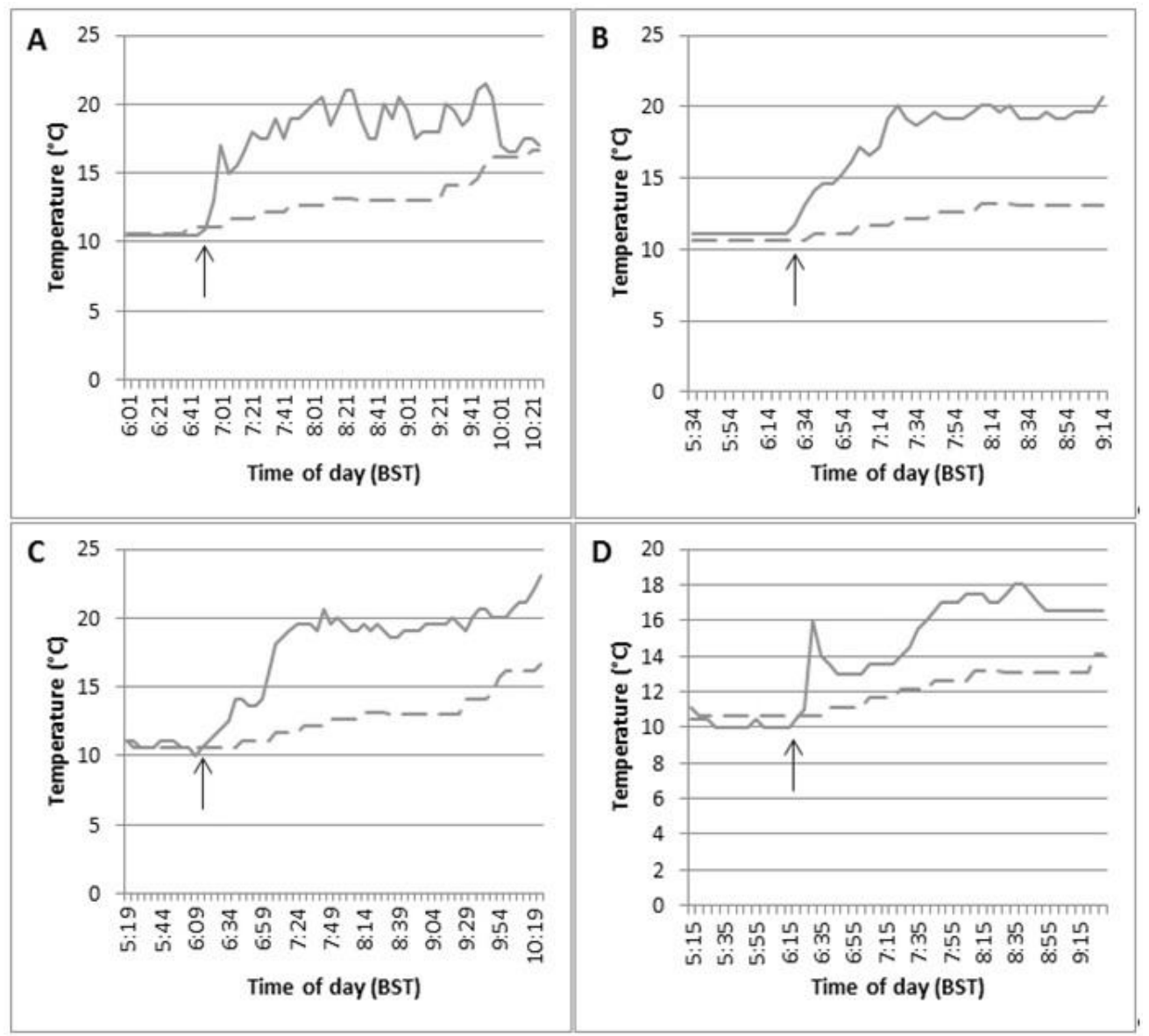

Fig. 1. Representative traces of internal trap temperature $\left({ }^{\circ} \mathrm{C}\right)$ over time during the period before and after capture of bank voles (solid line) versus temperature measured in traps without capture (dashed line). All data collected 7th June 2018. The black arrows show the estimated time when the animal entered the trap.

repeated exposure to the stressor). When there was an interval between capture of a vole of the same sex within the same transect the average interval between periods of capture was 217.5 minutes $( \pm 126.8 \mathrm{SD})$, with the shortest time difference being 102 minutes. Given the quick decrease of the glucocorticoid response after elimination of the stressor (Windle et al., 1998), and the fact that gut transit time, which affects the presence of glucocorticoid metabolites in faeces (Palme et al., 1996; von der Ohe \& Servheen, 2002), is short in small rodents (Clemens \& Stevens, 1980; Pei et al., 2001), we suggest that even if repeated capture of the same individual occurred, it would not have an impact on our estimation of the effect of trap confinement.

During explanatory analyses of cortisol concentrations versus trapping duration, there was no evidence of a delay between animals entering the trap and an increase in faecal cortisol concentrations, and therefore a linear relationship was assumed thereafter. The effect of sex, body mass, and the interaction between sex and duration on faecal cortisol concentrations were also investigated. Time of day was also added as a factor variable with four levels (morning: 6:00-10:00, midday: 10:00-14:00, afternoon: 14:00-18:00, evening: 18:00-22:00), as cortisol concentrations show a circadian variation (Windle et al., 1998), but it was eliminated later during model selection, together with the effect of body mass.
Cortisol values were log-transformed to better fit the assumptions of the linear model that were assessed by plotting the residuals against the fitted values and by checking the normality of the residuals on a QQ-plot. The alpha level (i.e. statistical significance) was set as $P<0.05$ and variance is represented by the standard deviation (SD), except when reporting model coefficients, where standard errors (SE) are given.

\section{RESULTS \\ Trapping}

The total number of captures was 39, including 37 bank voles, one wood mouse and one common shrew (Sorex araneus). The latter two were not included in the analysis. Double captures occurred on two occasions and in both cases one female and one male were trapped together. In two cases, the animals escaped during phenotypic assessment. In one case, only its sex was determined and in the other neither the mass nor the sex were determined. The average body mass of the trapped voles was $25.8 \pm 2.22 \mathrm{~g}$ for males and $27.5 \pm 3.07 \mathrm{~g}$ for females. The two sexes were equally represented and altogether we determined the cortisol values for 29 samples from trapped and 15 samples for non-trapped animals $\left(\mathrm{N}_{\text {males }}=13 ; \mathrm{N}_{\text {females }}=13 ; \mathrm{N}_{\text {undetermined }}=1 ; \mathrm{N}_{\text {double }}\right.$ capture $=2)$. The average time that the animals spent in the traps was $128.53 \pm 62.6$ minutes. 


\section{Stress response to trapping}

The faecal cortisol concentrations of the trapped animals did not differ significantly from those observed in the non-trapped individuals (Mann-Whitney $U$ test: $\mathrm{W}=$ $188, P=0.4771$, median $_{\text {non-trapped }}=0.23 \pm 0.21 \mathrm{ng} \mathrm{g}^{-1}$, median $_{\text {trapped }}=0.25 \pm 0.24 \mathrm{ng} \mathrm{g}^{-1}$; Fig. 2).

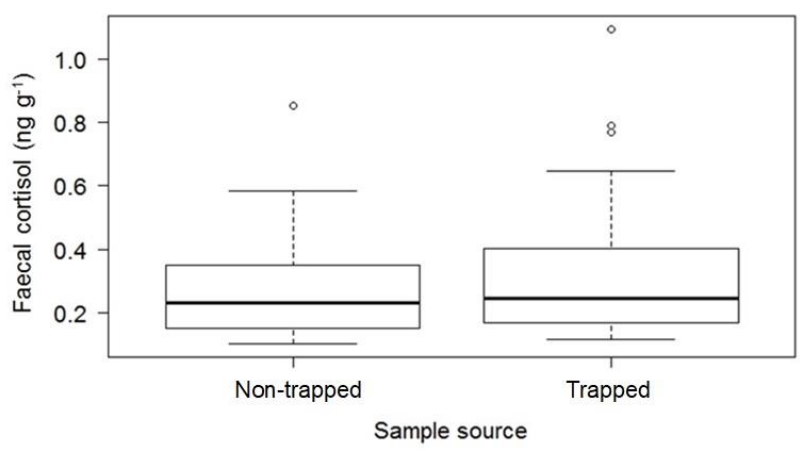

Fig. 2. Boxplot of faecal cortisol concentration (ng $\mathrm{g}^{-1}$ ) depending on the source of the sample. The non-trapped samples were collected from non-closing traps, while trap samples were from regular captures. The boxes represent the interquartile range with medians marked with thick line, while the whiskers represent 1.5 times the interquartile range.

\section{Stress response to the duration of being trapped}

The effect of trapping duration on the faecal cortisol concentration was significant $\left(\mathrm{F}_{1 ; 12}=5.11, P=0.043\right)$. The other variables did not have a significant effect (mass: $\mathrm{F}_{1 ; 12}=0.081, P=0.781$; time of day: $\mathrm{F}_{3 ; 12}=$ $0.978, P=0.435$; sex: $\mathrm{F}_{1 ; 4}=1.17, P=0.341$; sexduration interaction: $\mathrm{F}_{1 ; 12}=2.40, P=0.147$ ). After removing body mass and time of day as non-significant variables, the effect of trapping duration was also statistically significant, while the sex-duration interaction became marginally non-significant (duration: coef. $=-0.007 \pm 0.002 \mathrm{SE}, \mathrm{F}_{1 ; 17}=7.934, P=$ 0.012; sex: coef. $=-1.004 \pm 0.442 \mathrm{SE}, \mathrm{F}_{1 ; 4}=0.929, P=$ 0.389 ; sex-duration interaction: coef. $=0.006 \pm 0.003$ $\left.\mathrm{SE}, \mathrm{F}_{1 ; 17}=4.329, P=0.0529\right)$. In our final model, the random effect accounted for 0.194 SD with a residual variance of 0.434 . According to this model, the greater the duration of captivity the lower the faecal cortisol concentration. This effect was more pronounced in males than in females (Fig. 3). However, the interaction with sex was not significant. The data from individuals with a missing measurement for sex or mass were not included in the model.

\section{DISCUSSION}

This study investigated the effect of trapping duration on the physiological stress response of bank voles. The results obtained did not show a significant difference in the faecal cortisol concentrations in trapped voles relative to that seen in non-trapped voles but did show that cortisol concentrations decreased with the total duration of capture.

Temperature data loggers appear to be a useful tool to estimate the time when the animal entered the trap, and to calculate the exact duration of trapping. Bio-logging techniques such as this are becoming widely used

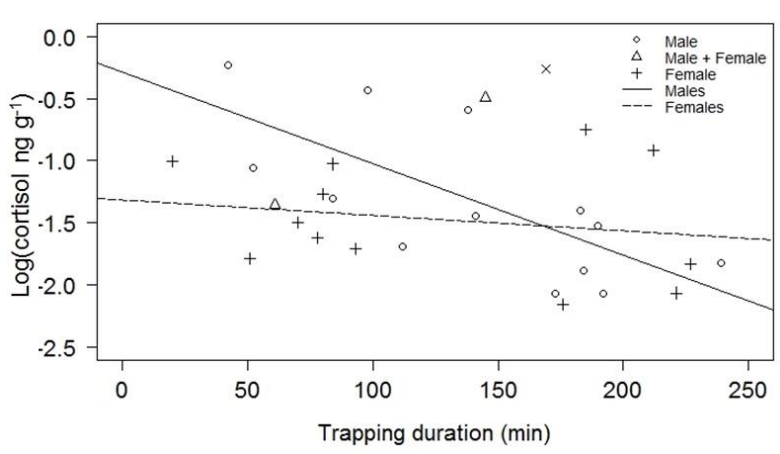

Fig. 3. Relationship between $\log$ faecal cortisol $\left(n \mathrm{ng}^{-1}\right)$ and trapping duration (minutes), depending on the sex of the captured animal. The continuous line shows the relationship for males and dashed line for females.

(Ropert-Coudert et al., 2009; Kukalová et al., 2013) and they have several advantages compared with traditional methods. In previous studies (e.g. Bosson et al., 2012; Fletcher \& Boonstra, 2006; Harper \& Austad, 2001) the standard method of estimating trapping duration is to check the traps at given intervals to see if an animal is present or absent, which provides only a rough estimate of the actual time of capture. Time is therefore often treated as a factor variable based on the sampling interval (e.g. every four or six hours). To analyse the progression of the stress response with time, this interval should be short, which would make the work timeconsuming with traditional methods, and the frequent checking of the traps could lead to an even more elevated stress responses in the animals. In contrast, ibutton $^{\mathrm{TM}}$ temperature-loggers can continuously collect data for several days without any human labour. As these loggers are able to detect a $0.5{ }^{\circ} \mathrm{C}$ change in temperature they can detect the time when an animal is captured, due to the heat produced by its body compared with the background value. Moore et al. (2010) reported that temperature data loggers (ibutton ${ }^{\mathrm{TM}}$ ) were suitable to remotely monitor nest box occupancy in two possum species (western ringtail possum Pseudocheirus occidentalis and common brushtail possum Trichosurus vulpecula), and our study also demonstrates their applicability to assess trap entry with small rodent species. With this method we were able to investigate the effect of capture duration on a continuous scale, rather than comparing distinct intervals.

Cortisol was successfully detected in bank vole faecal samples using the cortisol ELISA confirming it as a noninvasive method for physiological stress assessment in this species. From a welfare aspect, this was important as it could potentially substitute the use of blood cortisol measurements and avoided use of lethal snap traps (Fletcher \& Boonstra, 2006). According to our results, the faecal cortisol concentrations found in the samples collected from the trapped animals and the non-trapped animals were not significantly different, though comparison of these data is problematical: the latter, but not the former, were sampled during the night, and glucocorticoid hormone concentrations show a circadian rhythm (National Research Council, 2008). However, Windle et al. (1998) studied the interaction 
between this rhythm and stress response, and reported that corticosteroid concentrations during the latter - in response to acute noise stress - were higher by an order of magnitude than those measured at any time before stress, which makes it very unlikely that the impact of capture-induced stress would be overwhelmed by the effect of circadian variation.

The possible explanation for the lack of difference is that trapping did not elevate cortisol concentrations. However, as the more detailed analysis showed that cortisol concentrations were negatively correlated with trap duration, this result may suggest that any physiological stress response was short-lasting and the animals habituated to the trap and therefore the effects on faecal cortisol are not apparent when mean faecal cortisol concentration was determined from multiple collected faeces. The absence of an overall trapping effect and the indication that habituation may occur in the voles in this study contrasts with previous studies of small rodents (Harper \& Austad, 2001; Fletcher \& Boonstra, 2006; Bosson et al., 2012), where an increased stress response was seen over time. It is also possible that, after a critical duration of captivity, another peak of the stress response occurs, which may be linked to food availability or other factors. As the traps were checked at four hour intervals in this study (except in the one case of overnight trapping), the animals in our study were trapped for a much shorter time ( $c a .128$ minutes) than in previous studies and this may explain why any further cortisol response was not detected. Harper \& Austad (2001) found an elevated concentration of faecal corticosteroids in red-backed voles that were trapped for four hours $\left(c a .300 \mathrm{ng} \mathrm{g}^{-1}\right)$ or 12 hours ( $c a .700 \mathrm{ng} \mathrm{g}^{-1}$ ), which supports our hypothesis that a more pronounced stress response can be only observed when the trapping duration is much greater than in the current study. Similar results were found by Eleftheriou et al. (2020) in North American deer mice: the levels of faecal corticosteroid metabolites were lower in animals confined for zero to four hours compared with a longer confinement for eight to ten hours, and were also lower than after a short restraint. It is important to note that the cortisol values obtained in this study show an overall response during the period of confinement within the trap, as opposed to the stress level of the animal by the end of the period of captivity. Therefore we cannot predict that a vole being confined for four hours should be less stressed than another one captured for half as long, but the average response (if we assume that voles defecated within the whole period) of the former should be lower. As mentioned before, this response may consist of more "peaks": one early rise, e.g. due to the restriction of movement, which is followed by habituation, and a later one linked to the limited food availability or other factors. Habituation can also explain the pattern that we detected: the lower cortisol values associated with it can compensate the early higher response, resulting in a lower average value in animals confined for longer, while in the others we only detect the first peak, thus a higher average stress level. The best way to answer these questions and to assess how the stress response of animals changes over time would be to collect multiple droppings per animal without pooling them, making a comparison between maximum and minimum cortisol concentrations possible. For example, Rogovin et al. (2008) investigated faecal samples collected from trapped great gerbils (Rhombomys opimus) every 30 minutes during two hours of confinement, but they did not detect any corticosterone response related to time in the trap. In the same study, they also analysed seasonal and betweenyear variation of corticosterone levels, and reported average concentrations of $1.6-1.85 \mathrm{ng} \mathrm{g}^{-1}$ faeces, which is higher than the cortisol concentrations detected in our samples with the medians being $0.232 \mathrm{ng} \mathrm{g}^{-1}$ for nontrapped and $0.247 \mathrm{ng} \mathrm{g}^{-1}$ for trapped individuals. Further detailed studies like these are needed to better understand the physiological impact of short-term confinement and to design better trapping protocols.

It is also interesting that the negative effect of trapping duration was more pronounced in males than in females. In this species, both males and females maintain territories, but the territories of males are larger, and females prefer dominant males (Horne \& Ylonen, 1996). Losing a territory could have a higher fitness cost for males, which could be a possible explanation why males showed an elevated stress response to capture. Or in contrast, females become less habituated to trap confinement with the time, resulting in a higher average response for the whole captive period by longer captive durations (Fig. 3). These hypotheses would need further investigation of vole behaviour.

In conclusion, we successfully used faecal cortisol to assess the stress response of bank voles to live-trapping. Similar low concentrations of faecal cortisol were found in both open and closed traps suggesting no obvious stress response to (short term) trapping but faecal cortisol was negatively correlated with trap duration, indicating that this may have been a sampling artefact due to collecting the average cortisol concentration in faeces over time. Future studies would benefit from sampling faeces from known time intervals within the trap.

\section{ACKNOWLEDGEMENTS}

We would like to send special thanks to Callum Buchanan for helping in the ELISA assay. We would also like to thank the University of Glasgow for providing funding for the project and Scottish Centre for Ecology and the Natural Environment (SCENE) for logistical support. The work was undertaken by TD in partial fulfilment for the MSc Animal Welfare Science, Ethics and Law.

\section{REFERENCES}

Abelson, K.S., Adem, B., Royo, F., Carlsson, H.E. \& Hau, J. (2005). High plasma corticosterone concentrations persist during frequent automatic blood sampling in rats. In Vivo 19, 815-819.

Bertolino, S. \& Genovesi, P. (2003). Spread and attempted eradication of the grey squirrel (Sciurus carolinensis) in Italy, and consequences for the red 
squirrel (Sciurus vulgaris) in Eurasia. Biological Conservation 109, 351-358. https://doi.org/10.1016/S0006-3207(02)00161-1

Boonstra, R., McColl, C.J. \& Karels, T. (2001). Reproduction at all costs: the adaptive stress response of male arctic ground squirrels. Ecology 82, 1930-1946.

https://doi.org/10.1890/0012-9658(2001)082[1930: RAACTA]2.0.CO;2

Bosson, C.O., Islam, Z. \& Boonstra, R. (2012). The impact of live-trapping and trap model on the stress profiles of North American red squirrel. Journal of Zoology 288, 159-169. https://doi.org/10.1111/j.1469-7998.2012.00941.x

Bosson, C.O., Palme, R. \& Boonstra, R. (2009). Assessment of the stress response in Columbian ground squirrels: laboratory and field validation of an enzyme immunoassay for fecal cortisol metabolites. Physiological and Biochemical Zoology 82, 291-301. https://doi.org/10.1086/597530

Chelini, M.O.M., Otta, E., Yamakita, C. \& Palme, R. (2010). Sex differences in the excretion of fecal glucocorticoid metabolites in the Syrian hamster. Journal of Comparative Physiology B 180, 919-925. https://doi.org/10.1007/s00360-010-0467-9

Clemens, E.T. \& Stevens, C.E. (1980). A comparison of gastrointestinal transit time in ten species of mammal. Journal of Agricultural Science 94, 735737.

https://doi.org/10.1017/S0021859600028732

Dallman, M.F. \& Bhatnagar, S. (2001). Chronic stress and energy balance: role of the hypothalamopituitary-adrenal axis. In: McEwen, B.S. \& Goodman, H.M. (Editors.). Handbook of Physiology. Section 7: The Endocrine System: Coping with the Environment: Neural and Endocrine Mechanisms, Vol. IV, pp. 179-210. Oxford University Press, New York.

Dantzer, B., McAdam, A.G., Palme, R., Fletcher, Q.E., Boutin, S., Humphries, M.M. \& Boonstra, R. (2010). Fecal cortisol metabolite levels in free-ranging North American red squirrels: assay validation and the effects of reproductive condition. General and Comparative Endocrinology 167, 279-286. https://doi.org/10.1016/j.ygcen.2010.03.024

Eleftheriou, A., Palme, R. \& Boonstra, R. (2020). Assessment of the stress response in North American deermice: laboratory and field validation of two enzyme immunoassays for fecal corticosterone metabolites. Animals 10, 1120. https://doi.org/10.3390/ani10071120

Fletcher, Q.E. \& Boonstra, R. (2006). Impact of livetrapping on the stress response of the meadow vole (Microtus pennsylvanicus). Journal of Zoology 270, 473-478. https://doi.org/10.1111/j.1469-7998.2006.00153.x

Harper, J.M. \& Austad, S.N. (2000). Fecal glucocorticoids: a noninvasive method of measuring adrenal activity in wild and captive rodents. Physiological and Biochemical Zoology 73, 12-22. https://doi.org/10.1086/316721
Harper, J.M. \& Austad, S.N. (2001). Effect of capture and season on fecal glucocorticoid concentrations in deer mice (Peromyscus maniculatus) and red-backed voles (Clethrionomys gapperi). General and Comparative Endocrinology 123, 337-344. https://doi.org/10.1006/gcen.2001.7682

Horne, T. \& H. Ylonen. (1996). Female bank voles (Clethrionomys glareolus) prefer dominant males; but what if there is no choice. Behavioral Ecology and Sociobiology 38, 401-405. https://doi.org/10.1007/s002650050257

IUCN (2016). The IUCN Red List of Threatened Species. Version 2016-3. www.iucnredlist.org Accessed 7th December 2016.

Jung, T.S. (2016). Comparative efficacy of Longworth, Sherman, and Ugglan live-traps for capturing small mammals in the Nearctic boreal forest. Mammal Research 61, 57-64. https://doi.org/10.1007/s13364-015-0251-z

Kaufman, G.A. \& Kaufman, D.W. (1994). Changes in body mass related to capture in the prairie deer mouse (Peromyscus maniculatus). Journal of Mammalogy 75, 681-691. https://doi.org/10.2307/1382516

Kenagy, G.J. \& Place, N.J. (2000). Seasonal changes in plasma glucocorticosteroids of free living female yellowpine chipmunks: effects of reproduction and capture and handling. General and Comparative Endocrinology 117, 189-199. https://doi.org/10.1006/gcen.1999.7397

Korn, H. (1987). Effects of live-trapping and toeclipping on body weight of European and African rodent species. Oecologia 71, 597-600. https://doi.org/10.1007/BF00379304

Koprowski, J.L. (2002). Handling tree squirrels with a safe and efficient restraint. Wildlife Society Bulletin 30, 101-103.

Koskela, E., Mappes, T. \& Ylonen, H. (1997). Territorial behaviour and reproductive success of bank vole Clethrionomys glareolus females. Journal of Animal Ecology 66, 341-349. https://doi.org/10.2307/5980

Kukalová, M., Gazárková, A. \& Adamík, P. (2013). Should I stay or should I go? The influence of handling by researchers on den use in an arboreal nocturnal rodent. Ethology 119, 848-859. https://doi.org/10.1111/eth.12126

Lindner, E. \& Fuelling, O. (2002). Marking methods in small mammals: ear-tattoo as an alternative to toeclipping. Journal of Zoology 256, 159-163. https://doi.org/10.1017/S0952836902000195

MacDonald, D. \& Barrett, P. (1993). Collins Field Guide-Mammals of Britain and Europe. HarperCollins, London.

McEwen, B.S. \& Sapolsky, R.M. (1995). Stress and cognitive function. Current Opinion in Neurobiology 5, 205-216. https://doi.org/10.1016/0959-4388(95)80028-X

Mellish, J.E. (2010). A preliminary assessment of the impact of disturbance and handling on Weddell seals of McMurdo Sound, Antarctica. Antarctic Science 22, 25-29. https://doi.org/10.1017/S0954102009990447 
Mendl, M. (1999). Performing under pressure: stress and cognitive function. Applied Animal Behaviour Science 65, 221-244. https://doi.org/10.1016/S0168-1591(99)00088-X

Mills, J.N., Childs, J.E., Ksiazek, T.G., Peters, C.J. \& Velleca, W.M. (1995). Methods for Trapping and Sampling Small Mammals for Virologic Testing. U.S. Department of Health and Human Services, Washington D.C, U.S.A.

Moberg, G.P. \& Mench, J.A. (2000). The Biology of Animal Stress: Basic Principles and Implications for Animal Welfare. CABI, Wallingford. https://doi.org/10.1079/9780851993591.0000

Montiglio, P.O., Pelletier, F., Palme, R., Garant, D., Réale, D. \& Boonstra, R. (2012). Noninvasive monitoring of fecal cortisol metabolites in the eastern chipmunk (Tamias striatus): validation and comparison of two enzyme immunoassays. Physiological and Biochemical Zoology 85, 183193. https://doi.org/10.1086/664592

Moore, T., de Tores, P. \& Fleming, P.A. (2010). Detecting, but not affecting, nest-box occupancy. Wildlife Research 37, 240-248. https://doi.org/10.1071/WR09111

Nagy, K.A., Girard, I.A. \& Brown, T.K. (1999). Energetics of free-ranging mammals, reptiles, and birds. Annual Review of Nutrition 19, 247-277. https://doi.org/10.1146/annurev.nutr.19.1.247

National Research Council. (2008). Recognition and Alleviation of Distress in Laboratory Animals. The National Academies Press, Washington, DC, U.S.A.

Ortiz, R.M. \& Worthy, G.A. (2000). Effects of capture on adrenal steroid and vasopressin concentrations in free-ranging bottlenose dolphins (Tursiops truncatus). Comparative Biochemistry and Physiology A: Molecular and Integrative Physiology 125, 317-324. https://doi.org/10.1016/S1095-6433(00)00158-6

Palme, R., Fischer, P., Schildorfer, H. \& Ismail, M.N. (1996). Excretion of infused ${ }^{14} \mathrm{C}$-steroid hormones via faeces and urine in domestic livestock. Animal Reproduction Science 43, 43-63. https://doi.org/10.1016/0378-4320(95)01458-6

Pavone, L.V. \& Boonstra, R. (1985). The effects of toe clipping on the survival of the meadow vole (Microtus pennsylvanicus). Journal of Zoology 63, 499-501. https://doi.org/10.1139/z85-072

Pearson, O. (1947). The rate of metabolism of some small mammals. Ecology 28, 127-145. https://doi.org/10.2307/1930947

Pearson, E., Ortega, Y.K. \& Ruggiero, L.F. (2003). Trap induced mass declines in small mammals: mass as a population index. Journal of Wildlife Management 67, 684-691. https://doi.org/10.2307/3802675

Pearson, D.E. \& Ruggiero, L.F. (2003). Transect versus grid trapping arrangements for sampling smallmammal communities. Wildlife Society Bulletin 31, 454-459.

Pei, Y.X., Wang, D.H. \& Hume, I. (2001). Selective digesta retention and coprophagy in Brandt's vole
(Microtus brandti). Journal of Comparative Physiology B 171, 457-464.

https://doi.org/10.1007/s003600100195

Reeder, D.M., Kosteczko, N.S., Kunz, T.H. \& Widmaier, E.P. (2004). Changes in baseline and stress-induced glucocorticoid concentrations during the active period in free-ranging male and female little brown myotis, Myotis lucifugus (Chiroptera: Vespertilionidae). General and Comparative Endocrinology 135, 260-269. https://doi.org/10.1016/j.ygcen.2003.12.020

Rogovin, K.A. \& Naidenko, S.V. (2010). Noninvasive assessment of stress in bank voles (Myodes glareolus, Cricetidae, Rodentia) by means of enzyme-linked immunosorbent assay (ELISA). Biology Bulletin 37, 959-964. https://doi.org/10.1134/S1062359010090098

Rogovin, K.A., Randall, J.A., Kolosova, I.E. \& Moshkin, M.P. (2008). Long-term dynamics of fecal corticosterone in male great gerbils (Rhombomys opimus Licht.): effects of environment and social demography. Physiological and Biochemical Zoology 81, 612-626. https://doi.org/10.1086/588757

Romero, L.M. \& Reed, J.M. (2005). Collecting baseline corticosterone samples in the field: is under $3 \mathrm{~min}$ good enough? Comparative Biochemistry and Physiology A: Molecular \& Integrative Physiology 140, 73-79. https://doi.org/10.1016/j.cbpb.2004.11.004

Ropert-Coudert, Y., Beaulieu, M., Hanuise, N. \& Kato, A. (2009). Diving into the world of biologging. Endangered Species Research 10, 21-27. https://doi.org/10.3354/esr00188

Rosatte, R.C. \& MacInnes, C.D. (1989). Relocation of city raccoons. Proceedings of the Great Plains Wildlife Damage Conference 9, 87-92.

Stickel, L.F. (1954). A comparison of certain methods of measuring ranges of small mammals. Journal of Mammalogy 35, 1-15. https://doi.org/10.2307/1376067

Suazo, A.A. \& Delong, A.T. (2007). Responses of oldfield mice (Peromyscus polionotus) to consecutive days of live-trapping. American Midland Naturalist $158,395-402$.

https://doi.org/10.1674/0003-0031(2007)158[395:R OOMPP]2.0.CO;2

Teixeira, C.P., De Azevedo, C.S., Mendl, M., Cipreste, C.F. \& Young, R.J. (2007). Revisiting translocation and reintroduction programmes: the importance of considering stress. Animal behaviour 73, 1-13. https://doi.org/10.1016/j.anbehav.2006.06.002

Touma, C., Palme, R. \& Sachser, N. (2004). Analyzing corticosterone metabolites in fecal samples of mice: a noninvasive technique to monitor stress hormones. Hormones and Behavior 45, 10-22. https://doi.org/10.1016/j.yhbeh.2003.07.002

von der Ohe, C.G. \& Servheen, C. (2002). Measuring stress in mammals using fecal glucocorticoids: opportunities and challenges. Wildlife Society Bulletin 30, 1215-1225. 
Weidinger, K. (2006). Validating the use of temperature data loggers to measure survival of songbird nests. Journal of Field Ornithology 77, 357-364.

https://doi.org/10.1111/j.1557-9263.2006.00063.x

Wey, T.W., Lin, L., Patton, M.L. \& Blumstein, D.T. (2015). Stress hormone metabolites predict overwinter survival in yellow-bellied marmots. Acta Ethologica 18, 181-185. https://doi.org/10.1007/s10211-014-0204-6

Wilson, K.R. \& Anderson, D.R. (1985). Evaluation of two density estimators of small mammal population size. Journal of Mammalogy 66, 13-21. https://doi.org/10.2307/1380951

Windle, R.J., Wood, S.A., Shanks, N., Lightman, S.L. \& Ingram, C.D. (1998). Ultradian rhythm of basal corticosterone release in the female rat: dynamic interaction with the response to acute stress. Endocrinology 139, 443-450.

https://doi.org/10.1210/endo.139.2.5721 